\title{
Quantitative Influence of Antibody and Complement Coating of Red Cells on Monocyte-Mediated Cell Lysis
}

\author{
Roger J. Kurlander, Wendell F. Rosse, and Gerald L. Logue, The Department \\ of Medicine, Durham Veterans Administration Hospital, Durham, North Carolina \\ 27705, and the Myrtle-Bell Lane Laboratories of the Department of Medicine, \\ Duke University Medical Center, Durham, North Carolina 27710
}

\begin{abstract}
A B S T RACT Monocyte-mediated lysis in vitro of human red cells coated with measured amounts of immunoglobulin G (IgG) or complement were studied. $1,000-1,500$ molecules of IgG anti-D are necessary to effect measurable lysis, and lysis increases linearly with increasing levels of antibody sensitization. $100 \mu \mathrm{g} /$ $\mathrm{ml}$ of IgGl abolished lysis even at maximal levels of anti-D sensitization (15,000 molecules/cell). Two isoimmune IgG anti-A or anti-B antisera were 5 to 10 -fold less efficient in promoting phagocytosis or lysis per molecule of IgG bound; however, because of the greater antigen density of A or B, more than 100,000 molecules IgG/cell could be bound, producing equivalent lysis to anti-D-coated cells. Although inhibition by IgGl was similar at equivalent levels of sensitization with anti-A, anti-B, or anti-D at high levels of coating with anti-A or anti-B (not attainable with anti-D), lysis was not inhibited by IgG1. Cells coated with human complement components alone were not lysed by monocytes; however, complement coating augmented IgG-mediated lysis and reduced the quantity of anti-D necessary to produce lysis to less than 1,000 molecules/ cell. After thorough degradation of $\mathrm{C} 3 \mathrm{~b}$ by serum to C3d, complement augmentation persisted.
\end{abstract}

\section{INTRODUCTION}

In "autoimmune" hemolytic anemia, antibodies directed against antigens on the human red blood cell may effect a dramatic decrease in the red cell lifespan. Although some antibodies can activate complement and thus produce a lytic lesion in the membrane, others are unable to do so and yet mediate destruction of the red cell. This destruction of immunoglobulin

Portions of this work were presented to the American Society of Hematology in December 1976, Boston, Massachusetts.

Dr. Rosse is a Medical Investigator for the Howard Hughes Medical Institute.

Received for publication 28 July 1977 and in revised form 19 December 1977.
$(\mathrm{IgG})^{1}$-coated cells appears to be brought about by interaction of red cells and phagocytic cells and has been studied in vivo, both in animals (1) and man (2). Red cell coating with IgG but not other immunoglobulin classes facilitates sequestration and destruction of red cells by the spleen even at low levels of antibody sensitization (2). In vitro, IgG-coated, chromium-labeled red cells mixed with monocytes adhere as rosettes (3) and are phagocytosed with chromium release (4). These interactions may be inhibited by the presence of small quantities of unbound IgG; probably because IgG receptors on leukocytes are blocked competitively by unbound IgG $(3,5)$.

Complement coating also influences red cell monocyte interaction. In vivo, complement-coated cells in the absence of IgG coating are rapidly sequestered, primarily in the liver $(1,6,7)$, however many complement-coated cells are returned to the circulation and may have a normal subsequent survival in vivo (1). The release of sequestered cells is believed a result of degradation of the C3 bridge from red cell to reticuloendothelial cells by the enzyme inactivator of C3, C3INA, and other serum factors. In vitro immune adherence of C3coated red cells to monocytes (8), polymorphonuclear cells (9), and some lymphocytes (10) can be easily demonstrated. Phagocytosis of complement-coated red cells by monocytes and polymorphonuclear cells is minimal by comparison to IgG-coated cells $(11,12)$.

We have developed quantitative IgG and C3 antiglobulin consumption tests capable of measuring very small amounts of IgG (13) and C3 (14), and we have utilized these assays to determine the quantitative requirements of IgG and C3 coating to produce lysis of human red cells incubated with human peripheral blood mononuclear cells in vitro. The relative effi-

${ }^{1}$ Abbreviations used in this paper: FCS, fetal calf serum; IgG, immunoglobulin G; MEM, Eagle's Minimum Essential Medium; PBS, phosphate-buffered saline; VBS, Veronal-buffered saline. 
ciency of anti-D and naturally occurring anti-A or anti-B and the effect of complement coating on lysis in the presence and absence of unbound fluid phase IgG were examined and are reported in detail.

\section{METHODS}

Chromium labeling and antibody coating of human red cells. Human red cells were obtained with informed consent from normal volunteers of known blood type. Cells were stored in ACD for up to $1 \mathrm{wk}$. On the day of assay, $2-4 \times 10^{8}$ red cells were washed with $0.04 \mathrm{M}$ phosphate-buffered isotonic saline (PBS) adjusted to $\mathrm{pH} 7.4$, supplemented with $5 \%$ heat-inactivated fetal calf serum (FCS; Grand Island Biological Co., Grand Island, N. Y.). The cells were then incubated with $50-100 \mu \mathrm{Ci}$ of sodium chromate (New England Nuclear, Boston, Mass.) for $60 \mathrm{~min}$. Cells were washed four times, radioactivity was measured with a gamma emission spectrometer, and red cell concentration determined with a hemacytometer.

Human isoantibodies with anti-D or anti-A or anti-B specificity were used for red cell antibody sensitization. IgG anti-D concentrate obtained commercially (Rhogam, Ortho Pharmaceutical Corp., Raritan, N. J.) was the main source of anti-D antibody. Four additional sera with anti-D titers from 1:32 to $1: 256$ by indirect Coombs' assay were obtained from $\mathrm{Rh}_{0^{-}}$ negative women sensitized during pregnancy. A number of $\mathrm{O}+$ sera from normal individuals who had never been transfused were screened for anti-A or anti-B antibody activity in producing monocyte-mediated lysis of A or B red cells. One serum with predominantly anti- $\mathrm{A}$ and another with anti-B activity were heat inactivated at $56^{\circ} \mathrm{C}$ for $30 \mathrm{~min}$ and chromatographed on a Sephadex G-200 (Pharmacia Fine Chemicals, Piscataway, N. J.) column using $0.15 \mathrm{NaCl}$ for elution. The IgG peak was collected, concentrated using vacuum dialysis at $4^{\circ} \mathrm{C}$, dialyzed against $0.15 \mathrm{NaCl}$, and stored frozen at $-20^{\circ} \mathrm{C}$ for future use. The antibody preparations produced a precipitin line with anti-IgG but not anti-IgM on Ouchterlony assay.

Chromium-labeled or unlabeled cells were coated with antibody by incubating 0.1 or $0.2 \mathrm{ml}$ red cell suspension (1-8 $\times 10^{8} / \mathrm{ml}$, depending on the antibody) in PBS plus 5\% FCS with dilutions of antisera. After 60 min of incubation, cells were washed four times at $37^{\circ} \mathrm{C}$, a sample removed for use in the monocyte-mediated lysis assay, and the remainder assayed for cell-associated IgG.

IgG immunoassay of IgG-coated red cells. Immunoassay was performed with a modification of the quantitative antiglobulin consumption technique previously reported (13). Sheep cells chemically coated with purified human IgG are lysed by a constant limited quantity of rabbit antihuman IgG antibody in the presence of complement. Because unbound IgG competes with IgG-coated cells for limited anti-IgG, a reference curve relating inhibition of lysis with addition of known quantities of IgG can be produced and extrapolated to quantitate IgG content of an unknown sample.

Veronal buffered saline (VBS), rabbit antihuman (IgG, and guinea pig complement were prepared as previously reported (13). IgG-coated cells for these experiments were chemically coated with DEAE-purified monoclonal IgG1 by incubating $1 \mathrm{~cm}^{3}$ of saline-washed packed sheep red cells with $0.5 \mathrm{ml}$ of a $10-20 \mathrm{mg} / \mathrm{ml}$ solution of IgG and $0.14 \mathrm{ml}$ of $0.8 \%$ gluteraldehyde at room temperature for $60 \mathrm{~min}$. Cells were then washed three times with VBS and adjusted to $4.4 \times 10^{8}$ cells $/ \mathrm{ml}$. Cells were stable for 5-7 days after preparation.

A reference curve is produced by adding $0.1 \mathrm{ml}$ of a previously determined dilution of rabbit antihuman IgG to 0.1-ml dilutions of reference serum (Meloy Laboratories Inc., Spring- field, Va.) containing $15-600 \mu \mathrm{g} / \mathrm{ml}$ of IgG and incubating for $30 \mathrm{~min}$ at $37^{\circ} \mathrm{C} 0.1 \mathrm{ml}$ of coated sheep cells is then added and incubated for $30 \mathrm{~min}$, followed by addition of $0.2 \mathrm{~cm}^{3}$ of $1 / 20$ guinea pig complement and a final 30 -min incubation at $37^{\circ} \mathrm{C} .5 \mathrm{ml}$ of VBS is added, the tubes are centrifuged to sediment unlysed cells, and the OD determined at a wavelength of $412 \mathrm{~nm}$. Maximal anti-IgG-mediated lysis (OD max) in the presence of anti-IgG and complement without inhibiting IgG and background, nonspecific lysis $\left(\mathrm{OD}_{\text {blank }}\right)$ in the presence of guinea pig complement without IgG or anti-IgG are both determined in duplicate. The log OD test-OD blank OD max-OD blank i.e., the log of unlysed cells/lysed cells is linearly related to the $\log$ IgG concentration in nanograms (15). The optimal line describing the relationship of these variables is calculated with a programmable Hewlett-Packard model HP-65 calculator (Hewlett-Packard Co., Palo Alto, Calif.) using the Hewlett-Packard program for the least squares method.

To assay red cell IgG antibody coating, dilutions of human red cells are incubated with anti-IgG-coated sheep cells and complement, as above, in parallel with the IgG standard. To correct for spontaneous and complement-mediated lysis of the human red cells which would interfere with determination of sheep cell lysis, duplicate samples of antibody-coated human red cells were' incubated with anti-IgG and guinea pig serum with $0.1 \mathrm{ml}$ of VBS in place of the coated sheep cell reagent (OD color control). Hence:

$\log$ (unlysed cells/lysed cells $)=\log (\mathrm{OD}$ test-OD color controlOD blank/OD max-OD blank).

Cell-associated IgG is extrapolated from the IgG reference line expressed in nanograms per milliliter and converted to molecules per cell because the red cell concentration is known. The molecular weight of IgG was assumed to be 160,000 daltons in these calculations.

Nonspecific IgG attachment to cells lacking the antigen was determined in parallel with specific antibody measurement and was subtracted from total red cell-associated IgG to calculate the net level of antibody coating. The IgG assay can detect $<500$ molecules/cell of antibody coating.

IgG subclass immunoassay of IgG antibody-coated human red cells. The principle described above was applied to the evaluation of IgG subclass composition of human antired cell antibodies. Purified monoclonal IgG1, IgG2, IgG3, and IgG4 and highly specific, anti-subclass antisera prepared in rabbits were kindly donated by Dr. William Yount of North Carolina Memorial Hospital. Four separate sheep cell reagents were prepared by chemically coating sheep cells with each of the purified subclass proteins, using either gluteraldehyde or $\mathrm{CrCl}_{3}$ (13). When matched subclass-specific antisera and complement were added as described above, lysis could be measured. Multiple experiments using purified IgG subclass proteins confirmed that inhibition of lysis of subclassspecific sheep cells by matched antisera was only produced by IgG of the same subclass. Inhibition of lysis by heavily anti-D-, anti-A-, or anti-B-coated human red cells was measured with each of the subclass-specific assays simultaneously, and the presence of more than $40 \%$ inhibition of any of the subclass assays was considered to confirm the presence of antibody activity of that subclass.

Leukocyte-mediated lysis assay. Effector leukocytes were obtained from $30-50 \mathrm{ml}$ of heparinized blood collected from normal donors after informed consent, using sterile technique. A gelatin solution (Plasmagel, Roger Bellon Laboratory, Inc. Neuilly, France) was added ( $2 \mathrm{ml}$ for each $10 \mathrm{ml}$ of blood), and red cells were allowed to settle for $1 \mathrm{~h}$. White cell-rich plasma was then separated and, in some experiments, incubated with carbonyl iron (GAF Corp., New York), 1 g/10 ml plasma for 
30 min with frequent agitation. Phagocytic cells and excess carbonyl iron were removed with a magnet. The leukocyte preparation or monocyte-depleted lymphocyte preparation was then carefully layered in $20 \mathrm{~cm}^{3}$ of Ficoll-Hypaque solution $50 \%$ Hypaque and $9 \%$ Ficoll in a $1: 3$ ratio by volume with a specific gravity of 1.080; Pharmacia Fine Chemicals) and centrifuged at $1,000 \mathrm{~g}$ for $20 \mathrm{~min}$. The leukocyte layer was removed from the interface and washed three times with Eagle's Minimum Essential Medium (MEM; Grand Island Biological) and suspended in McCoy's 5A media with 15\% FCS, with $25 \mathrm{mM}$ Hepes buffer (Sigma Chemical Co., St. Louis, Mo.) and $20 \mu \mathrm{l} / \mathrm{ml}$ of penicillin and streptomycin solution (Grand Island Biological). Cell concentration was adjusted to $1 \times 10^{7} / \mathrm{ml}$.

Leukocyte-mediated lysis was measured in triplicate using a round-bottomed microtiter plate (Cooke Laboratory Products Div., Dynatech Laboratories, Inc., Alexandria, Va.). 10 $\mu l$ of labeled washed red cells, either precoated with antibody and washed three times as described above, or coated in situ by addition of $10 \mu \mathrm{l}$ of antisera to the microtiter plate, was incubated with $100 \mu \mathrm{l}$ of leukocyte suspension at rest, at $37^{\circ} \mathrm{C}$, in a moisturized $5 \% \mathrm{CO}_{2}$ incubator. After incubation, $100 \mu \mathrm{l}$ of saline was added to all samples, and the microtiter plate centrifuged at $2,500 \mathrm{rpm}$ for $10 \mathrm{~min} .100 \mu \mathrm{l}$ was then removed from each sample well for determination of radioactivity due to $\mathrm{Cr}^{51}$. Maximal $\mathrm{Cr}^{51}$ release was determined by adding 100 $\mu \mathrm{l}$ of $0.9 \% \mathrm{NH}_{4} \mathrm{Cl}$ in place of saline. Maximal release $\left(\mathrm{cpm}_{\max }\right)$ varied from 500 to $2,000 \mathrm{cpm}$. Incubation of uncoated red cells with monocytes for $3.5 \mathrm{~h}$ never caused more than $1 \%$ more chromium release than incubation without monocytes, but in some experiments heavy sensitization with antibody and/or complement precoating (see below) increased spontaneous chromium release in the absence of monocytes up to $10 \%$. Therefore, lysis was calculated using the formula: \% antibodydependent leukocyte-mediated lysis $=([\mathrm{cpm}$ with antibodycoated red blood cells + leukocytes - cpm with antibodycoated red blood cells without leukocytes] $/\left(\mathrm{cpm}_{\max }\right) \times 100$. The standard error was calculated by determining the standard error of difference (16) of triplicate determinations of the first term of the numerator of Eq. 1, assuming the $\mathrm{cpm}_{\max }$ to be constant between samples. Linear regression analysis was performed using a Hewlett-Packard computer program. The $P$ value of the linear regression results were determined from the tables of Fisher and Yates (17).

Simultaneous measurement of chromium-labeled red cell release and sequestration within leukocytes. Phagocytosis of chromium-labeled, antibody-coated red cells was assessed simultaneously with the measurement of chromium release using a modification of the method of Mantovani et al. (18) which exploits the finding that red cells phagocytosed by leukocytes are no longer susceptible to osmotic lysis by hypotonic saline. Red cells $\left(1 \times 10^{5}\right.$ in $\left.20 \mu \mathrm{l}\right)$ and leukocytes $(1$ $\times 10^{6}$ in $1 \mathrm{~cm}^{3}$ ) were mixed and incubated for $2-3.5 \mathrm{~h}$ at $37^{\circ} \mathrm{C}$ in a $5 \% \mathrm{CO}_{2}$ incubator, as described above. However, the assay was performed in $12 \times 75-\mathrm{mm}$ disposable glass tubes (Corning Glass Works, Corning, N. Y.) instead of a microtiter plate. After incubation, $0.9 \mathrm{~cm}^{3}$ of $0.15 \mathrm{NaCl}$ was added to all tubes and the tubes were spun in a Serofuge (Clay Adams, Div. of Becton, Dickinson \& Co., Parsippany, N. J.) for 3 min, $0.5 \mathrm{~cm}^{3}$ of supernatant fluid removed, and the percent of chromium released calculated by the formula described earlier.

The remaining $0.5 \mathrm{~cm}^{3}$, containing leukocytes and unlysed red cells, was gently agitated to resuspend the pellet, $2 \mathrm{~cm}^{3}$ of distilled water was added, and the tube mixed to produce a hypotonic suspension of $0.03 \mathrm{M} \mathrm{NaCl}$. This was incubated at room temperature for $90 \mathrm{~s} .1 \mathrm{ml}$ of $0.45 \mathrm{M} \mathrm{NaCl}$ was added to return the suspension to isotonicity, the tube was then recentrifuged, and the supernatant fluid discarded. The pellet was washed twice with $\mathrm{PBS}$ and then the retained radioactivity of ingested red cells measured. Retained radioactivity of uncoated red cells incubated with leukocytes after hypotonic shock $\left(\mathrm{cpm}_{\text {control }}\right)$ and the total radioactivity of $1 \times 10^{5} \mathrm{red}$ cells $\left(\mathrm{cpm}_{\max }\right)$ also were determined. $\mathrm{Cpm}_{\text {control }}$ was $<5 \%$ of $\mathrm{cpm}_{\max }$. The percent of antibody-coated cells specifically phagocytosed was calculated by the formula: \% phagocytosis of antibody-coated red cells $=(\mathrm{cpm}$ with antibody-coated red blood cells + leukocytes - cpm with control red cells + leukocytes/(cpm $\max ) \times 100$.

Quantitation of phagocytosis by visual determination. Phagocytosis was also measured by a variant of the method of Ehlenberger and Nussenzweig (19). Monocyte monolayers were prepared by incubation of $20 \mu \mathrm{l}$ of the $1 \times 10^{7} / \mathrm{cm}^{3}$ suspension of leukocytes on a $22 \times 22-\mathrm{mm}$ coverslip for $30 \mathrm{~min}$. After incubation, the nonadherent cells were removed from the coverslip by gentle washing with PBS. Then the coverslip was flooded with a $2 \times 10^{8} / \mathrm{cm}^{3}$ suspension of antibody-coated, washed red cells. The coverslip was incubated for $45 \mathrm{~min}$ at $37^{\circ} \mathrm{C}$ in a $5 \% \mathrm{CO}_{2}$ incubator and then gently rinsed to remove nonadherent, nonphagocytosed red cells. The slide was then exposed to $0.0375 \mathrm{M} \mathrm{NaCl}$ for $15 \mathrm{~s}$ to lyse adherent red cells that can visually obscure phagocytosed red cells, and the slide was rapidly air dried and stained with Wright's stain. More than $90 \%$ of adherent cells were monocytes by morphologic criteria. The percent of leukocytes containing one or more phagocytosed red cells was determined by visual inspection of at least 300 adherent leukocytes under a microscope at $\times 970$ with an oil immersion objective lens.

Inhibition of lysis by unbound IgG. IgGl was obtained by DEAE-cellulose purification of serum from a patient with high levels of monoclonal IgG1. Purified IgG2, IgG3, and IgG4 were kindly provided by Dr. William Yount of North Carolina Memorial Hospital.

Inhibition of lysis by unbound IgG was determined by adding $10 \mu \mathrm{l}$ of appropriate IgG dilutions to antibody-coated red cells before the addition of leukocytes. Assay was then performed as usual, and lysis in the presence of $\operatorname{IgG}$ compared to lysis by control cells incubated without added IgG and assayed simultaneously.

Complement coating of human red cells and measurement of cell-bound total C3. Human cells were coated with complement components by incubating equal volumes of $\mathrm{O}+$ red cells at a concentration of $4.4 \times 10^{8} / \mathrm{cm}^{3}$ with dilutions of a high titer anti-I cold agglutinin containing antiserum and a $1: 2$ dilution of fresh frozen $\mathrm{AB}$ human serum at $0^{\circ} \mathrm{C}$ for $10 \mathrm{~min}$. The mixture was then warmed to $37^{\circ} \mathrm{C}$ in a water bath over a 10-min period, and washed three times in PBS with 5\% FCS. In some experiments, a portion of the coated cells were then incubated with $\mathrm{AB}$ serum heated at $56^{\circ} \mathrm{C}$ for $30 \mathrm{~min}\left(1 \mathrm{~cm}^{3} /\right.$ $2.2 \times 10^{8}$ packed red cells) for $3 \mathrm{~h}$ to degrade $\mathrm{C} 3 \mathrm{~b}$ to $\mathrm{C} 3 \mathrm{~d}$.

Complement-coated cells were assayed for total C3 using a method previously described (14). The assay measures inhibition of lysis of C3-coated, trypsinized sheep cells by anti-C3 in the presence of guinea pig serum in a manner analogous to the IgG assay. Complementing coating was expressed in molecules C3/cell, assuming a C3 molecular weight of 185,000 daltons. Untreated cells had no detectable complement coating; however, incubation with 1:100 dilutions of cold agglutinin resulted in coating with 40,000-80,000 molecules/cell.

C3b Immunoassay of complement-coated human red cells. The C3 assay described above measures all molecules of C3 fixed to the membrane regardless of their molecular form. This is because the antibody(ies), the absorption of which is measured, is (are) directed against antigen(s) common to all molecular forms of C3 (C3, C3b, C3d) bound to the membrane. Antibodies against other antigens present on the $\mathrm{C} 3$ molecule only when intact, or on the C3c portion, are not measured because 
these antigens are removed from the C3 coating of the detector sheep cells by the treatment with trypsin. When C3bcoated human cells are incubated with heated serum to convert the membrane-bound C3b to C3d, the total amount of C3 on the cells detected with trypsinized $\mathrm{E}^{\text {sh }} \mathrm{C} 3$ remains the same.

In sensitizing a series of rabbits with $\mathrm{C} 3$ antigen by methods previously described (14), the antiserum from a single rabbit was found to detect antigens present on native $\mathrm{C} 3$, and on C3b- and C3d-coated red cells. The precipitin lines formed after immunoelectrophoresis of partially aged serum confirmed antibody activity against $\mathrm{C} 3 \mathrm{c}$ and native $\mathrm{C} 3$ but not against the C3d fragment. This antiserum was used to develop an assay for cell bound C3b coating. As expected, this antibody did not lyse $E^{\text {sh }} \mathrm{C} 3$ that had been trypsinized but did lyse untrypsinized $\mathrm{E}^{\text {sh }} \mathrm{C} 3$; therefore, untrypsinized $\mathrm{E}^{\text {sh }} \mathrm{C} 3$ were used as the detector cells in the assay. The lysis of the detector cells was inhibited by C3 in fluid phase but not by C4, C5, or IgG. When cells were coated with complement as described above, approximately $60 \%$ of the C3 on the cells is in the form of $\mathrm{C} 3 \mathrm{~b}$, and $3 \mathrm{~h}$ of incubation with heated serum destroys all detectable $\mathrm{C} 3 \mathrm{~b}$ on coated cells.

\section{RESULTS}

Experimental conditions. Red cells of group A or B incubated with $10 \mu \mathrm{l}$ of anti-A or anti-B directly for $30 \mathrm{~min}$ followed by addition of $1 \times 10^{6}$ leukocytes demonstrated specific antibody-dependent, monocyte-mediated lysis. Anti-D (anti-Rh ${ }_{0}$ ) did not produce analogous lysis with cells containing $\mathrm{D}\left(\mathrm{Rh}_{\mathbf{0}}\right)$ antigen unless unbound antisera were thoroughly washed from the system before incubation with monocytes.

The time-course of lysis of anti-D-coated, washed red cells was rapid, with $70-80 \%$ of total observed lysis completed within $3.5 \mathrm{~h}$ (see Fig. 1). Additional incubation frequently increased nonspecific lysis, so a $3.5-\mathrm{h}$ incubation period was selected for subsequent experiments.

Antibody-specific, cell-mediated lysis was studied at varying leukocyte to red cell ratios using washed, anti-D-coated cells by incubating $1 \times 10^{6}$ leukocytes with $5-20 \times 10^{4}$ red cells, and the percent lysis was nearly constant within this range. $1 \times 10^{5}$ red cells per microtiter well (a 10:1 leukocyte to red cell ratio) were used in subsequent studies because minor variations in white blood cell:red blood cell ratio from sample to sample would not influence lysis.

Identification of effector cell of lysis. Ficoll-Hypaque-purified normal leukocytes contained 15-30\% monocytes as determined by phase microscopy, peroxidase, or Wright-Giemsa staining, 70-85\% lymphocytes and, usually $<1 \%$ polymorphonuclear cells. This preparation produced up to $40 \%$ lysis in the presence of maximally anti-D-coated cells in microtiter plates and up to $50 \%$ lysis in $12 \times 75$-mm tubes. Complete and partial erythrophagocytosis by monocytes was readily visible by phase microscopy after $3.5 \mathrm{~h}$ of incubation, and, for most donors, $<5 \%$ lysis was seen after monocyte depletion using carbonyl iron to remove most phagocytic cells. Phase microscopy confirmed the

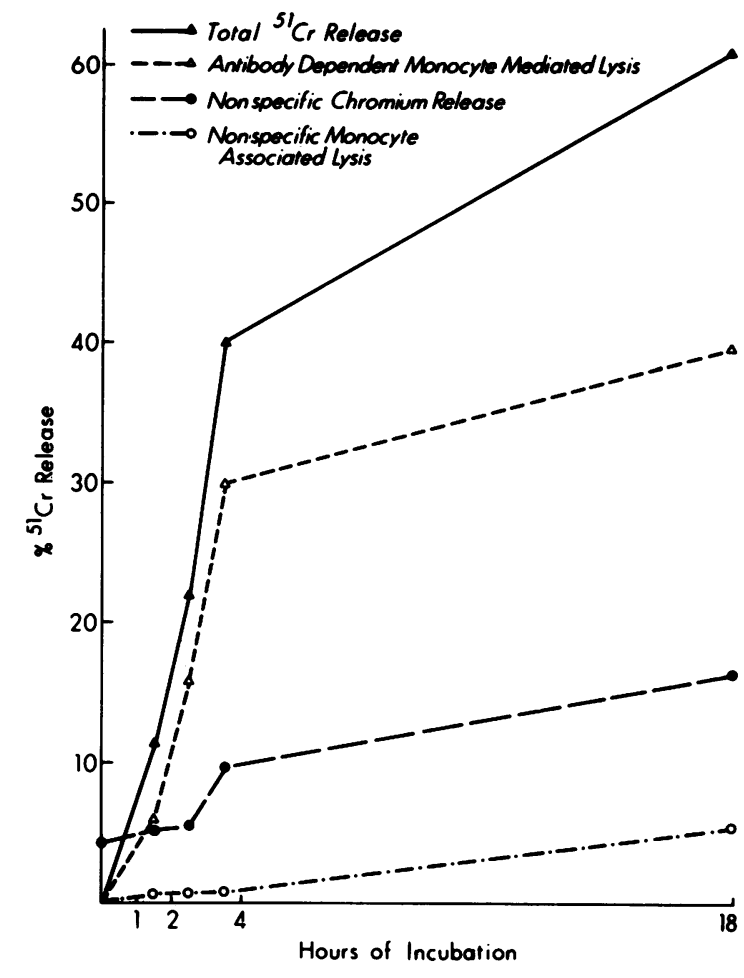

Figure 1 Time-course of lysis of anti-D-coated $\mathrm{O}^{+}$human red cells by monocytes. Nonspecific chromium release from red cells coated with antibody in the absence of monocytes and nonspecific monocyte-associated lysis of uncoated red cells increase continuously with time, but antibody-dependent, monocyte-mediated lysis occurs primarily during the first $3.5 \mathrm{~h}$ of incubation.

absence of erythrophagocytosis after monocyte depletion. The data indicate monocyte-mediated lysis is the predominant mechanism of lysis under these conditions.

To decrease day-to-day variability, a single donor with active monocyte-mediated lysis which could be completely eliminated with carbonyl iron treatment was utilized exclusively in the following experiments.

Relationship of monocyte-mediated chromium release and red cell phagocytosis. Intracellular chromium sequestration and release of chromium into solution from human red cells heavily coated with anti-D was measured simultaneously after 2 and $3.5 \mathrm{~h}$ of incubation in $12 \times 75$-mm glass tubes. There was considerable variability in the amount of intracellular chromium sequestration (a measure of phagocytosis) at similar levels of chromium release even though a single leukocyte donor was used in all experiments (Table I). At one extreme (experiment A), there was $23.1 \%$ chromium sequestration and $13.5 \%$, release after $2 \mathrm{~h}$ of incubation with a significant drop in sequestered chromium by $3.5 \mathrm{~h}$ to $10.5 \%$, whereas chromium release had increased to $22.8 \%$. At the other extreme (experi- 
TABLE I

Anti-D-Coated, Chromium-Labeled Red Cell Sequestration and Release after 2 and 3.5 Incubation with Leukocytes

\begin{tabular}{ccccccc}
\hline & \multicolumn{2}{c}{$2 \mathrm{~h}$ Incubation } & & \multicolumn{2}{c}{$3.5 \mathrm{~h}$ Incubation } \\
\cline { 2 - 3 } \cline { 5 - 6 } $\begin{array}{c}\text { Experi- } \\
\text { ment }\end{array}$ & $\begin{array}{c}\text { Intracellular } \\
\text { chromium } \\
\text { sequestration }\end{array}$ & $\begin{array}{c}\text { Chromium } \\
\text { release }\end{array}$ & & $\begin{array}{c}\text { Intracellular } \\
\text { chromium } \\
\text { sequestration }\end{array}$ & $\begin{array}{c}\text { Chromium } \\
\text { release }\end{array}$ \\
\hline & \multicolumn{2}{c}{$\%$} & & & \multicolumn{2}{c}{$\%$} \\
A & $23.1 \pm 1.9$ & $13.3 \pm 0.9 *$ & & $10.5 \pm 1.9$ & $22.8 \pm 1.9$ \\
B & $10.3 \pm 1.0$ & $8.7 \pm 1.0$ & & $9.5 \pm 3.4$ & $24.0 \pm 3.4$ \\
C & $1.0 \pm 0.8$ & $18.6 \pm 1.6$ & & $1.2 \pm 1.2$ & $39.8 \pm 0.7$ \\
D & $3.4 \pm 0.9$ & $15.0 \pm 0.9$ & & $2.0 \pm 0.4$ & $48.7 \pm 1.4$ \\
\hline
\end{tabular}

$* \pm \mathrm{SE}$

ment D), there was $<3.5 \%$ intracellular sequestration at 2 and $3.5 \mathrm{~h}$, although lysis was $15.0 \%$ at $2 \mathrm{~h}$ and $48.7 \%$ by $3.5 \mathrm{~h}$. Despite this variability in the degree of measurable ingestion associated with chromium release, significant sequestration was not observed in the absence of measurable chromium release in experiments using anti-D, anti-A, and anti-B.

Intracellular chromium sequestration after $2 \mathrm{~h}$ of incubation (the time of maximal measureable sequestration) and chromium release after incubation for $3.5 \mathrm{~h}$ with antibody-coated red cells at a concentration of 1 $\times 10^{6} / \mathrm{cm}^{3}$ were compared with phagocytosis, measured by visual identification of leukocytes containing ingested red cells after incubation of the same red cells at a concentration of $2 \times 10^{8} / \mathrm{cm}^{3}$ with a monocyte monolayer for $45 \mathrm{~min}$, were compared at several levels of anti-D antibody coating (Table II). Both chromium sequestration and release were undetectable at 500 molecules/cell of anti-D coating, whereas visually detectable phagocytosis was still apparent with that amount but not with 200 molecules/cell of anti-D coating per cell.

Quantitative comparison of anti-D and anti-A or

TABLE II

Comparison of the Sensitivity of Assays of ChromiumLabeled Red Cell Sequestration, Chromium Release, and Phagocytosis of AntiD-Coated Red Cells

\begin{tabular}{cccc}
\hline $\begin{array}{c}\text { Anti-D coating } \\
\text { (molecules/cell) }\end{array}$ & $\begin{array}{c}\text { Chromium } \\
\text { released }\end{array}$ & $\begin{array}{c}\text { Chromium } \\
\text { sequestered } \\
\text { intercellularly }\end{array}$ & $\begin{array}{c}\text { \% Leukocytes with one } \\
\text { or more phagocytosed } \\
\text { red cells }\end{array}$ \\
\hline & after $3.5 h$ & after $2 h$ & after 4.5 min \\
5,400 & $48.7 \pm 1.4^{*}$ & $3.4 \pm 0.9$ & 49.5 \\
1,200 & $18.8 \pm 1.2$ & $0.8 \pm 0.6$ & 35.0 \\
500 & 0 & $0.8 \pm 0.7$ & 7.1 \\
200 & 0 & $0.7 \pm 0.6$ & 0 \\
\hline
\end{tabular}

$* \pm \mathrm{SE}$.
anti-B coating in producing cell-mediated lysis. $\quad \mathrm{Cr}^{51}-$ labeled $\mathrm{O}+$ cells were coated with anti-D, washed four times with PBS, and assayed simultaneously for IgG antibody coating and for lysis in the presence of human leukocytes in microtiter plates. The collected results of multiple experiments using a purified anti-D from hyperimmune donors and sera from four patients with anti-D activity associated with pregnancy are shown in Fig. 2. Despite the varying sources of antibody, there is a linear relationship between quantity of anti-D coating and lysis, with $r=0.69$ and $P<0.001$. Detectable monocyte-mediated lysis, in most experiments, required 1,000-1,500 molecules/cell of anti-D, a quantity of antibody sufficient to produce complete agglutination with antiglobulin serum.

Anti-A- or anti-B-mediated lysis was also studied using cells of group A or B sensitized with anti-A or anti-B antisera from two donors under identical conditions. At all antibody coating levels, anti-A and anti-B were strikingly less efficient than anti-D in promoting monocyte-mediated lysis (Fig. 3). With either antibody, lysis of $5 \%$ of the cells required in excess of 10,000 molecules/cell, and marked lysis required very high levels of sensitization.

Quantitative comparison of anti-D and anti-A or anti-B coating in producing phagocytosis. Unlabeled red cells were coated with anti-D or anti-A or anti-B as described above, and incubated with a monocyte monolayer at a red cell concentration of $2 \times 10^{8} / \mathrm{cm}^{3}$. After incubation for $45 \mathrm{~min}$, the present of adherent leukocytes with phagocytosis was determined (Fig. 4). Anti-D-coated red cells were phagocytosed actively

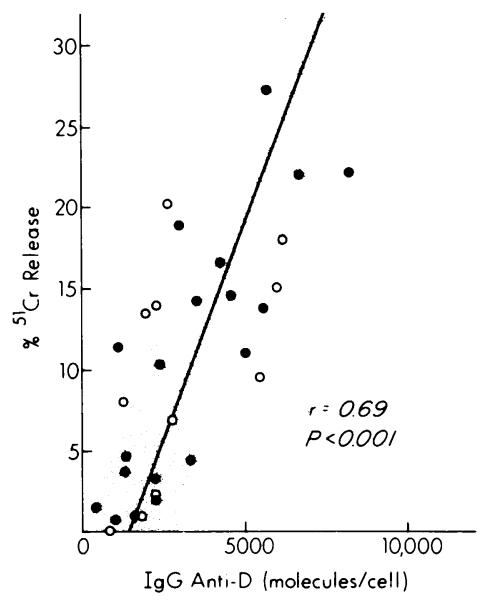

FIgURE 2 Quantitative relationship of anti-D coating of red cells to monocyte-mediated lysis. $1,500-2,000$ molecules of anti-D were required to produce significant lysis, and lysis was linearly related to the level of anti-D. Red cells were coated either with a pooled IgG anti-D preparation (closed circles) or antisera from four patients sensitized against D $\left(\mathrm{Rh}_{0}\right)$ antigen during pregnancy (open circles). 


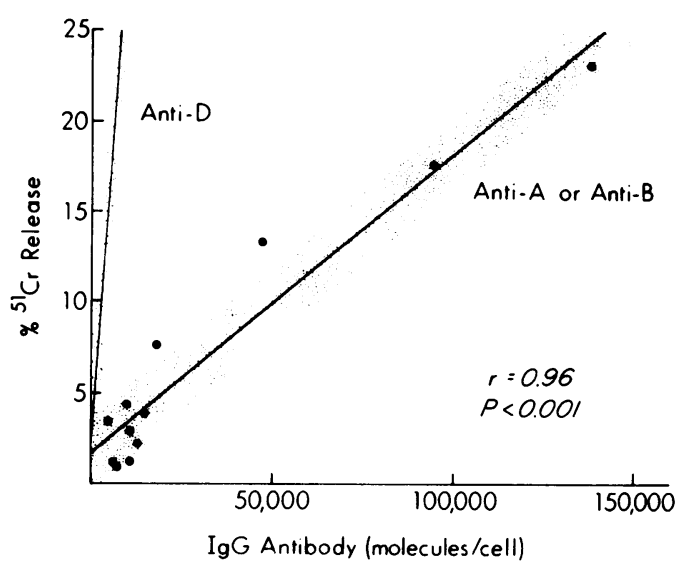

FIGURE 3 Quantitative relationship of antibody coating of red cells with anti-A or anti-B to monocyte-mediated lysis. About 10,000 molecules of anti-A or anti-B were required to produce significant lysis, and the degree of lysis per molecule bound antibody was much less than encountered with anti-D coating (lightly hatched line).

even with 1,600 molecules/cell coating. Although anti-A or anti-B coating in these experiments did not produce any agglutination, both antibodies were nonetheless markedly less efficient than anti-D in promoting phagocytosis. At a level of coating up to 9,000 molecules/cell, anti-A or anti-B produced less phagocytosis than anti-D at a level of 1,600 molecules/cell.

Subclass composition of anti-D and anti-A or anti-B

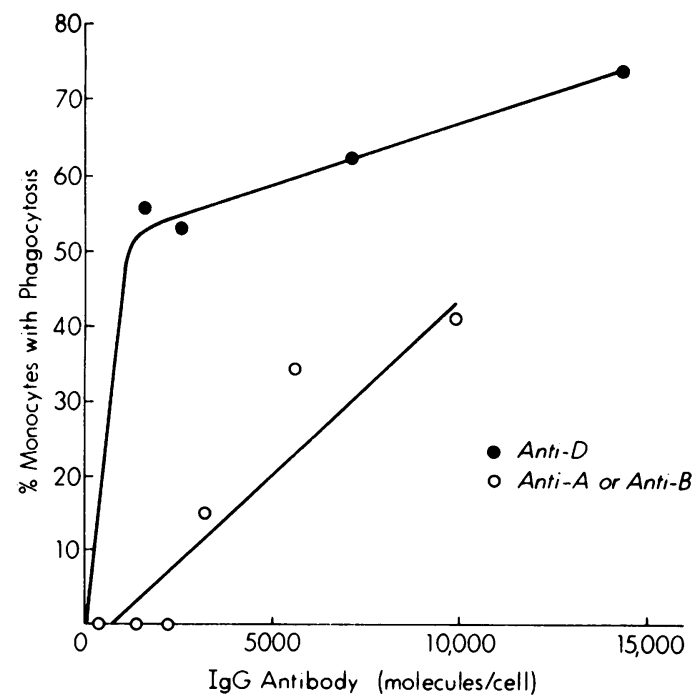

FIgURE 4 Quantitative relationship of anti-D and anti-A or anti-B coating to phagocytosis by monocytes. More than $50 \%$ of monocytes phagocytosed one or more red cells within 45 min when incubated with a $2 \times 10^{8} / \mathrm{cm}^{3}$ suspension of red cells coated with 1,600 molecules per cell of anti-D. 9,000 molecules of anti-A or anti-B per cell did not affect this level of phagocytosis.



FIGURE 5 Inhibition of monocyte-mediated lysis of anti-Dcoated washed cells by fluid phase IgG subclasses. IgGl and IgG3 are much more able than IgG2 and IgG4 to inhibit lysis.

antibodies. $\mathrm{O}+$ red cells incubated with purified IgG hyperimmune anti-D were coated with IgG1, IgG3, and IgG4 antibodies. Group A cells were coated with IgG 1, IgG3, and IgG4 by the anti-A antisera, and group B cells were coated with IgG1 and IgG2 by anti-B antisera.

Inhibition of lysis by unbound IgG. Lysis of $\mathrm{C}^{51}$. labeled $\mathrm{O}+$ cells by anti-D was inhibited by unbound IgG. When IgG1, IgG2, IgG3, and IgG4 are compared, IgG 1 and IgG3 are almost 100 -fold more effective than IgG2 and IgG4 per microgram added in inhibiting monocyte-mediated lysis (Fig. 5). For the remaining experiments, monoclonal IgG 1 was used as a referenceinhibiting protein.

Fig. 6 demonstrates inhibition of lysis by IgG1 at several anti-D concentrations. Increasing intensity of antibody coating decreases inhibition only slightly even with maximal attainable coating with 15,000

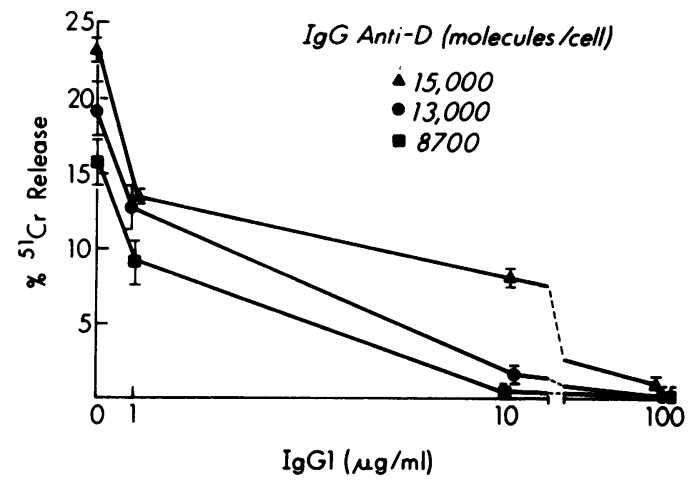

FIGURE 6 The effect of increasing levels of sensitization with anti-D on the inhibition of monocyte-mediated lysis by unbound IgG1. Greater antibody coating decreases IgGl inhibition of lysis but $100 \mu \mathrm{g} / \mathrm{ml}$ IgG $\mathrm{l}$ inhibits lysis even with maximal levels of anti-D sensitization. 




FIGURE 7 The effect of increasing levels of sensitization with anti-A and(or) anti-B on inhibition of monocyte-mediated lysis by unbound IgG $\mathrm{l}$. With very large amounts of anti-A or anti-B on the cell, inhibition does not occur (closed triangles), but with lesser amounts of coating (closed squares and circles), there is inhibition similar to that observed with equivalent levels of anti-D coating (open triangles).

molecules/cell. This potent inhibition explains the necessity for thorough washing of anti-D-coated cells before lysis can be demonstrated.

At high levels of anti-A or anti-B coating, even if antisera were not washed from the system, lysis was not inhibited by IgG 1 or even by undiluted serum. Inhibition of lysis by IgG 1 with lower levels of sensitization, however, was quite similar to inhibition of cells precoated with 15,00 molecules/cell of anti-D (Fig. 7).

Effect of complement coating on lysis and inhibition by unbound IgG1. Specific monocyte-mediated lysis of heavily complement-coated red cells was not seen even with very high levels of C3 coating $(79,000$ molecules/cell) despite abundant red cell monocyte rosetting under the phase microscope. However, when cells were precoated with complement, using a cold agglutinin and human serum before anti-D sensitization, lysis was significantly greater than lysis of cells not coated with complement at similar levels of IgG coating (Fig. 8). Detectable lysis of complement-coated cells required smaller quantities of IgG coating (Fig. 9). 1,000 molecules IgG/cell produced no lysis without C3 coating but red cells were significantly lysed if also complement coated.

Fluid phase IgGl inhibits lysis of IgG-coated cells almost completely even in the presence of large amounts of C3 coating (Fig. 10).

The effect of serum-mediated degradation of $\mathrm{C} 3 \mathrm{~b}$ was studied by incubating complement-coated cells with heated serum for $3 \mathrm{~h}$. After subsequent coating with anti-D, chromium release of serum-treated cells was increased compared with lysis of identically anti-

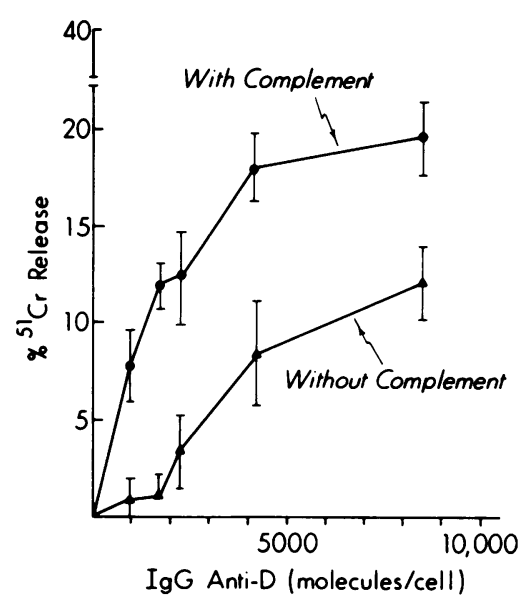

Figure 8 Augmentation of anti-D-mediated lysis by precoating red cells with complement. Red cells with 30,000 molecules of C3 fixed per cell, and cells without complement on the membrane were coated with the same amount of anti-D and incubated with monocytes. Lysis was augmented by complement at all levels of antibody coating, although complement alone on the membrane produced no monocyte-mediated lysis.

D-coated cells without complement precoating. Chromium release, however, was less than that produced by C3-coated cells incubated in PBS during the 3-h incubation to preserve C3b activity (Fig. 11).

To confirm that augmentation by complement despite serum incubation is simply not the result of residual nondegraded C3b, total C3 and C3b were simultaneously measured on samples of the above experiment. Noncomplement-coated cells had no detectable

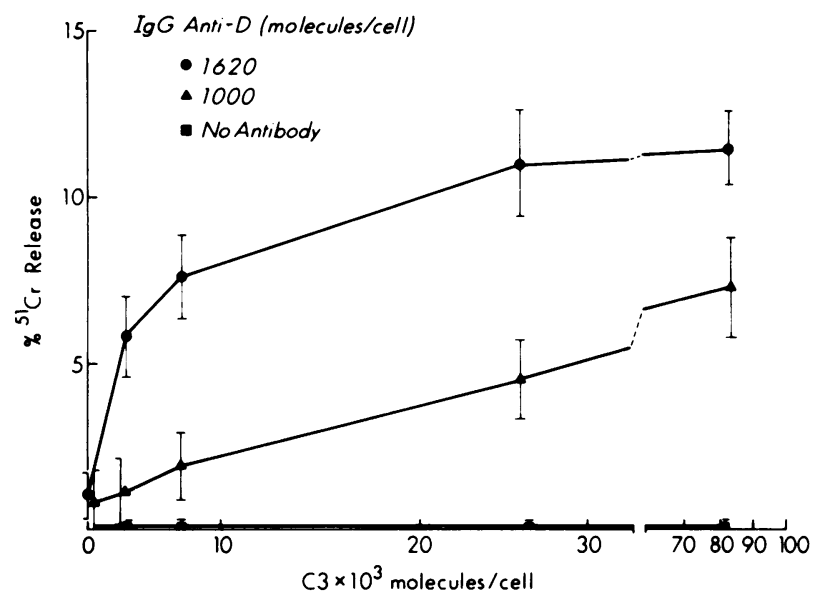

Figure 9 The effect of increasing levels of membrancbound complement components on monocyte-mediated lysis by small quantities of anti-D. Cells were coated with increasing amounts of complement and then were coated with antibody, washed, and assayed for IgG, C3, and monocyte-mediated lysis. Low levels of antibody producing virtually no lysis alone cause marked lysis after complement coating. 


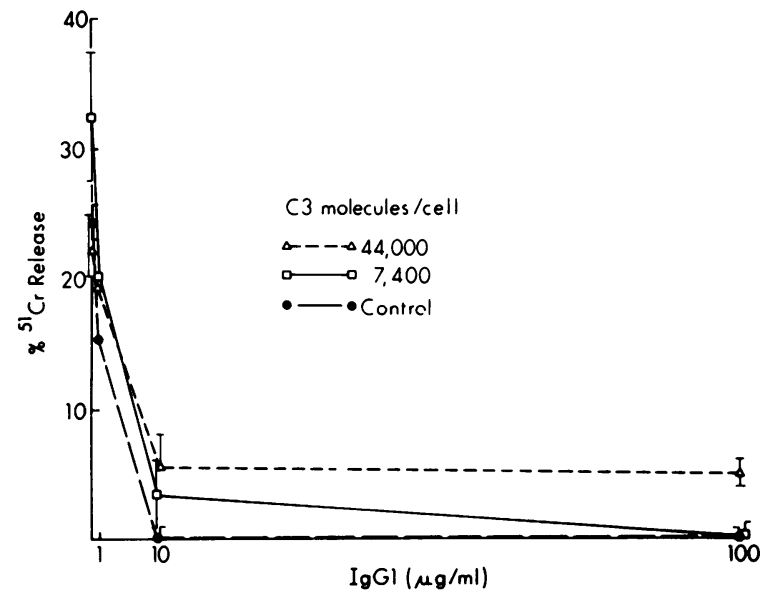

FIGURE 10 The effect of complement coating on inhibition of anti-D-dependent lysis by IgG1. Lysis of cells coated with complement components in addition to anti-D (open squares and triangles) was markedly inhibited by $100 \mu \mathrm{g} / \mathrm{ml} \mathrm{IgGl} \mathrm{much}$ as was lysis of cells coated with anti-D without complement (closed circles).

C3 by either assay. Complement-coated cells incubated in PBS for $3 \mathrm{~h}$ had 44,000 molecules of total $\mathrm{C} 3 /$ cell with 8,500 molecules of detectable C3b. The relatively low proportion of $\mathrm{C} 3 \mathrm{~b}$ is presumably the result of C3INA-mediated degradation during the complement fixation process (with serum as the source of

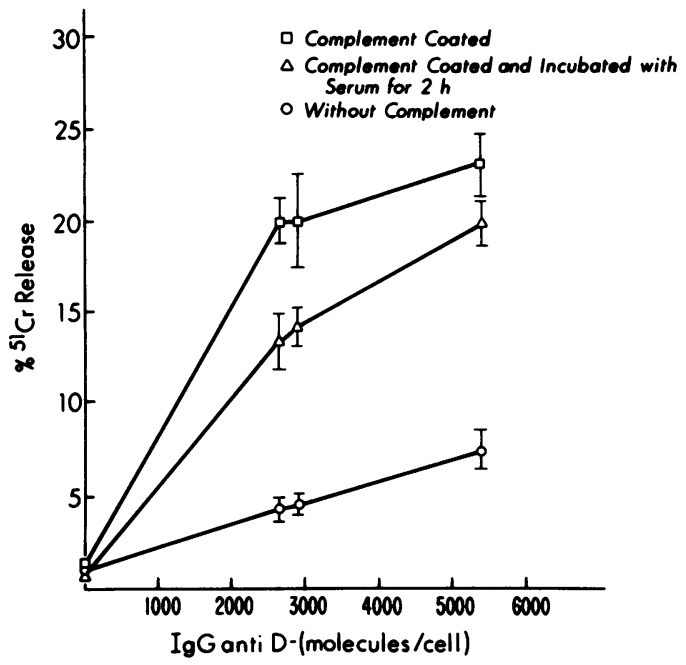

FIGURE 11 The effect of a 3-h incubation with serum on complement-mediated augmentation of lysis of anti-D-coated red cells. Cells precoated with complement and then incubated for $3 \mathrm{~h}$ at $37^{\circ} \mathrm{C}$ in PBS (open squares) serum (open triangles), or uncoated control cells (open circles), then were anti-D coated, washed, and assayed for IgG, total C3, C3b, and monocyte-mediated lysis (see text). Despite complete degradation of $\mathrm{C} 3 \mathrm{~b}$, serum-treated cells still demonstrated augmented lysis compared with cells not precoated with complement. complement) and spontaneous degradation during the 3-h incubation in PBS. Cells incubated for $3 \mathrm{~h}$ in heatinactivated serum had 48,000 molecules/cell of total C3 but no detectable $\mathrm{C} 3 \mathrm{~b}$. Thus, in addition to $\mathrm{C} 3 \mathrm{~b}$, other complement components (probably C3d) can augment release in these experiments.

\section{DISCUSSION}

The human monocyte is an effective mediator of antibody-dependent cell-mediated lysis in vitro. Although other effector cells mediating lysis have been identified, the monocyte was the effector cell in these experiments. Depletion of phagocytic cells from the mononuclear cells isolated on a Ficoll-Hypaque gradient by carbonyl iron treatment completely removed cells capable of effecting lysis, indicating the absence of significant effector activity by lymphocytes. This agrees with the findings of others $(5,20)$.

The destruction of labeled red cells by monocytes with release of ${ }^{51} \mathrm{Cr}$-labeled hemoglobin into the media can occur either by phagocytosis of the red cells with intracellular lysis and release of labeled hemoglobin from the monocyte or by direct cytolysis of the red cells on contact with monocyte membrane, without ingestion. In time-lapse motion pictures taken in our laboratory, both mechanisms, phagocytosis and direct cytolysis of anti-D-coated human cells by monocytes, can be seen to occur (12). However, direct cytolysis is a fleeting event, very difficult to identify or quantitate morphologically, and impossible to distinguish from phagocytosis with subsequent isotope release by measuring supernatant fluid radioactivity.

To study the relationship of phagocytosis and lysis, we adapted the method of Mantovani et al. (18) for detecting phagocytosed red cells by their resistance to osmotic lysis within the cytoplasm of monocytes. Unfortunately, measurement of the amount of ingestion alone is not sufficient information to determine the contribution of phagocytosis to total chromium release without knowledge of the average time from ingestion until release of hemoglobin into the media. In some experiments, phagocytosis was extensive and actually decreased in quantity between 2 and $3.5 \mathrm{~h}$, the period when chromium release was rising most sharply. In these experiments, phagocytosis with release of ingested chromium was almost certainly an important mechanism in producing lysis; however, in other experiments, phagocytosis remained minimal despite marked release. Unless red cells were being ingested and lysed with release of ingested hemoglobin at a very rapid rate, it is likely that most chromium release in these experiments was mediated by direct cytolysis. We have not yet identified the factors responsible for this variability in the degree of phagocytosis observed.

In experiments to measure the level of anti-D anti- 
body coating required to produce red cell-monocyte interaction, the assay of visually detectable phagocytosis was more sensitive than the assay of chromium release in detecting low levels of antibody coating. It is likely that this difference is a quantitative reflection of increased red cell-leukocyte interaction as a result of the assay conditions, inasmuch as visually determined phagocytosis is measured at a red cell concentration 200 -fold greater than used in the chromium release assay. Because chromium-labeled red cell sequestration, an assay of phagocytosis performed at the same low red cell concentration used to measure chromium release, did not appear more sensitive to low levels of antibody coating than chromium release, the variation in sensitivity probably does not reflect any basic difference in sensitivity of phagocytosis and direct cytolysis to low levels of antibody coating.

Both the anti-A and the anti-B antisera tested were considerably less efficient than anti-D in vitro in producing red cell phagocytosis or lysis. The reason for the decreased efficiency of the anti-A and anti-B antisera compared to anti-D is unknown. In vitro agglutination can occur at high levels of coating, and this might impede monocyte-red cell contact. However, this is not the sole explanation because agglutination was absent at levels of sensitization below 10,000 molecules/cell, yet significantly lower levels of phagocytosis and lysis also were found in this range of coating.

Inasmuch as the immunoassay for IgG on the red cell measures all subclasses of IgG, it is possible that the differences observed in the lytic efficiency might be due to the differences in the distribution of the subclasses because the subclasses differ in their ability to mediate adherence and effector cell interaction (21). However, the anti-D and the anti-A and anti-B did not differ significantly in the distribution of the subclasses; all antisera contained IgG3 and/or IgGl antibodies. Differences in antibody-antigen affinity and perhaps geometric considerations, such as pattern of antigen distribution and relative antigen mobility (22) within the bilayer, may account for the observed differences. More extensive studies will be necessary before we can distinguish whether the observed variability in efficiency is related to differences in antigen structure between $R h_{0}$ and $A$ and $B$, or to differences in physical characteristics between antibodies in response to bacterial antigens constantly present in the intestine (anti-A and anti-B) and antibodies in response to discrete parenteral sensitization with red cell antigen by blood transfusion or pregnancy.

Monocytes possess a receptor specific for the $\mathrm{Fc}$ portion of IgG1 and IgG3 antibody molecules, and this receptor is critical for the interaction of antibody-coated red cells and the monocyte (21). This receptor can also interact with fluid phase IgG1 and IgG3 at a concentration relatively greater than that present on the sur- face of the sensitized red cell; this interaction with fluid phase IgG inhibits the interaction with cell-bound $\operatorname{IgG}(3,5,21)$. Previous workers have shown that this inhibition of interaction, as measured by rosette formation or phagocytosis, is lessened by increasing the concentration of cell-bound antibody which, however, was not quantitated (23).

In our experiments, lysis mediated by anti-D was completely blocked by $10-100 \mu \mathrm{g} / \mathrm{ml}$ of unbound IgG 1 or IgG3. The relatively small number of antigen sites for anti-D on the red cell limited sensitization to 15,000 molecules of anti-D/cell. This level of antibody appears to be insufficient to overcome inhibition by $100 \mu \mathrm{g} / \mathrm{ml}$ of IgG1 or IgG3. On the other hand, the very much greater number of antigen sites for anti-A or anti-B permits the fixation of sufficient antibody to overcome the inhibition by fluid phase IgG. At similar levels of sensitization by the two antibodies, the degree of inhibition at a given concentration of fluid phase IgG appeared to be about the same. For a given degree of monocyte-mediated lysis, ten times as many molecules of anti-A or anti-B as anti-D must be fixed to the red cell; hence, under these conditions, inhibition of a given degree of lysis by fluid phase IgG will be correspondingly less for the former antibodies than for the latter.

The presence of complement components on the red cell surface appears to be very effective in promoting adherence to effector cells but much less potent in stimulating phagocytosis $(11,12)$. The third component of complement has been thought to be the most important of the components mediating adherence (8) although recently $\mathrm{C} 4$ has also been implicated (24). By our present method of complement fixation, $60-80 \%$ of the $\mathrm{C} 3$ on the red cell surface is in the form of C3b, as measured by $\mathrm{C} 3 \mathrm{~b}$-specific antisera, and the ratio of $\mathrm{C} 3$ to C4 fixed to the cells is about 10:1(14). Thus, immunoassay of total C3 measured the principle component(s) involved in immune adherence. The other components of complement that may be present on the cells (C5-C9) are not thought to take part in immune adherence.

In our studies, 80,000 molecules of $\mathrm{C} 3$ per red cell did not produce significant monocyte-mediated chromium releases. This suggests that the ineffectiveness of complement by itself in promoting cell-dependent lysis cannot be overcome even with maximal complement coating. However, the fixation of smaller amounts of complement markedly augments the effectiveness of IgG in promoting cell-mediated lysis. As a result, an amount of IgG insufficient to effect lysis by itself may become effective when complement is present. When the "active" form of C3, C3b, was degraded to C3d by C3INA and other serum factors, there was only a slight reduction in the augmentation of antibody-mediated lysis compared to that effected by the undegraded C $3 \mathrm{~b}$ 
molecule. This suggests that the immune adherence postulated by others for the C3d molecule (10) is effective in promoting antibody-dependent, monocytemediated lysis.

Ehlenberger and Nussenzweig (19) have also studied the effect of complement on IgG-mediated monocytered cell interaction. Using phagocytosis of sheep red cells coated with rabbit IgG, anti-sheep red cell antibody, and purified human complement components by monocytes to quantitate interaction, they have shown a decrease in the threshold IgG required to produce phagocytosis and augmentation of lysis at a constant level of IgG coating by concurrent C3b or C3d coating. These findings are fundamentally quite similar to our findings in a system using human components. However, their system was moderately more sensitive to low levels of IgG coating than ours. These differences are most likely attributable to a number of technical differences between the two systems, such as the use of a phagocytosis system instead of a chromium release assay (discussed above), the use of sheep cells, which are smaller and may be more easily phagocytosed than human red cells, and the use of a heterologous antiserum that may be more efficient than the human antibody used in our experiments. Of interest, those authors stress that augmentation by complement or other agents augmenting adherence is even more striking when the suspension is shaken during incubation. Because reticuloendothelial sequestration occurs in the presence of continuous blood flow, complement-mediated augmentation may be even more dramatic in vivo than in our experiments.

The use of quantitative assays in vitro may help to explain previous observations in vivo. The variability in efficiency of lysis in vitro for a given number of molecules of IgG antibody bound to human red blood cells by different antisera may be an in vitro correlate for the variability noted in hemolysis at similar levels of antibody coating in patients with immune hemolytic anemia $(25,26)$. The finding that the presence of complement on the cell along with IgG may increase the destruction of the cells by monocytes may correlate with the finding that the amount of hemolysis for a given degree of IgG on the cell surface is greater if complement is fixed than if it is not (27). Further, the finding that this effect is still seen after degradation of C3b to C3d, i.e., that C3d can mediate the same effect, may be important in interpreting the role of complement in vivo because very little $\mathrm{C} 3 \mathrm{~b}$ is present on the circulating cells in the patient.

The application of these assays to the study of monocyte-mediated lysis permits us to assess quantitatively the validity of this in vitro model proposed to explain in vivo hemolysis. The relationship of IgG coating to lysis demonstrated in these experiments is internally consistent but neither assay is capable of detecting 200 molecules of anti-D coating per cell, a level well within the ranges known to decrease red cell survival in vivo $(2,26)$. The increased sensitivity in vivo is almost certainly, at least in part, a result of the role of the spleen.

In vivo, red blood cells delivered to the spleen are concentrated in the macrophage-rich splenic cords by the process of plasma skimming, and then must traverse the narrow pores to return to the general circulation. The combination of very intimate macrophagered cell contact and physical distortion of the red cell in traversing the splenic pores has not yet been reproduced in vitro. In addition, red cells flow through the spleen at least 40 times a day and even more times through the liver. A degree of destruction with each passage, not detectable by an in vitro assay, could be magnified cumulatively with time and produce significant shortening of red cell survival. Thus, this discrepancy does not represent a conceptual obstacle to the acceptance of the monocyte-red cell interaction as the mechanism of red cell destruction in immune hemolysis.

More puzzling is the complete inhibition not only of chromium release but also of phagocytosis and rosetting by the presence of small amounts of unbound IgG. We have shown that lysis can proceed even in the presence of undiluted serum if red cells are very heavily antibody coated; this cannot account for most lysis in vivo which occurs at much lower levels of antibody coating, as reviewed above. Others have reported that complement coating markedly decreases inhibition of lysis of sheep red cells coated with antibody by unbound IgG (28), but a similar experiment in our system using only human components failed to confirm these findings. Thus, hemolysis of red cells coated with low levels of antibody, despite the presence of unbound IgG in serum, is not explicable solely as a result of concurrent complement coating.

It is probable that the properties of the reticuloendothelial system noted above also account for red cell destruction in vivo despite the presence of serum IgG by greatly facilitating weak cell-cell interactions completely undetected with current in vitro systems. This failure in detection remains a critical flaw in the current models, and an in vitro model capable of lysis under physiologic conditions remains a goal if we are to understand fully the mechanism by which cells are destroyed in vivo.

\section{ACKNOWLEDGMENTS}

We are deeply indebted to Ms. Judy P. Adams for technical assistance in these experiments, and to Ms. Norma Martell for help in preparation of the manuscript.

This research was supported by Research and Education funds from the Durham Veterans Administration Hospital and, in part, by National Institutes of Health grant R01-CA10267-10. 


\section{REFERENCES}

1. Schreiber, A. D., and M. M. Frank. 1972. The role of antibody and complement in the immune clearance of erythrocytes. I. In vivo effects of IgG and IgM complement fixing sites. J. Clin. Invest. 51: 575-582.

2. Mollison, P. L., and N. C. Hughes-Jones. 1967. Clearance of $\mathrm{Rh}$ positive red cells by low concentrations of $\mathrm{Rh}$ antibody. Immunology. 12: 63-73.

3. LoBuglio, A. F., R. S. Cotran, and J. H. Jandl. 1967. Red cells coated with immunoglobulin $\mathrm{G}$ : binding and sphering by mononuclear cells in man. Science (Wash. D. C.). 118: $1582-1585$.

4. Holm, G., and S. Hammarström. 1973. Haemolytic action of human blood monocytes: lysis of human erythrocytes treated with anti-A serum. Clin. Exp. Immunol. 13: 29-43.

5. Holm, G., E. Engwall, S. Hammarström, and J. B. Natwig. 1974. Antibody induced hemolytic activity of human monocytes. Scand. J. Immunol. 3: 173-180.

6. Brown, D. L., P. J. Lachmann, and J. V. Dacie. 1970. The in vivo behavior of complement coated red cells: studies in C6 deficient, C.3 depleted and normal rabbits. Clin. Exp. Immunol. 7: 401-421.

7. Mollison, P. L. 1970. The role of complement in antibody mediated red cell destruction. Br.J. Haematol. 18: 24925.5.

8. Huber, H., M. J. Polley, H. H. Fudenberg, and H. J. Müller-Eberhard. 1968. Human monocytes: distinct receptor sites for the third component of complement and for immunoglobulin G. Science (Wash. D. C.). 162: 12811283.

9. Mantovani, B. 1975. Different roles of IgG and complement receptors in phagocytosis by polymorphonuclear leukocytes. J. Immunol. 115: 15-18.

10. Ross, G. D., M. J. Polley, E. M. Rabellino, and H. M. Grav. 1973. Two different complement receptors in human lymphocytes: one specific for $\mathrm{C} 3 \mathrm{~b}$ and one specific for C.3b inactivator-cleaved C3b. J. Exp. Med. 138: 798811.

11. Bianco, C., F. M. Griffin, Jr., and S. C. Silverstein. 1975. Studies of the macrophage complement receptor: alteration of receptor function upon macrophage activation. $J$. Exp. Med. 141: 1278-1290.

12. Rosse, W. F., A. deBoisfleury, and M. Bessis. 1975. The interaction of phagocytic cells and red cells modified by immune reactions: comparison of antibody and complement coated red cells. Blood Cells. 1: 345-358.

13. Dixon, R., W. F. Rosse, and L. Ebbert. 1975. Quantitative determination of antibody in idiopathic thrombocytopenic purpura. N. Engl. J. Med. 292: 230-236.
14. Rosse, W. F., G. L. Logue, J. Adams, and J. H. Crookston. 1974. Mechanism of immune lysis of the red cells in hereditary erythroblastic multinuclearity with a positive acidified-serum test (HEMPAS) and paroxysmal nocturnal hemoglobinuria (PNH). J. Clin. Invest. 53: 31-43.

15. Kabat, E. A., and M. M. Mayer. 1961. Experimental Immunochemistry. Charles C. Thomas Publisher, Springfield, Ill. 2nd edition. 135-139.

16. Mainland, D. 1963. Elementary Medical Statistics. W. B. Saunders Company, Philadelphia. 2nd edition. 290.

17. Fisher, R. A., and F. Yates. 1963. Statistical Tables for Biologic Agricultural and Medical Research. Hafner Publishing Company Inc., New York. 63.

18. Mantovani, B., M. Rabinovitch, and V. Nussenzweig. 1972. Phagocytosis of immune complexes by macrophages: different roles of the macrophage receptor sites for complement (C3) and immunoglobulin (IgG). J. Exp. Med. 135: 790-792.

19. Ehlenberger, A. G., and V. Nussenzweig. 1977. The role of membrane receptors for C3b and C3d in phagocytosis. J. Exp. Med. 145: 357-369.

20. Poplack, D. G., G. D. Bonnard, B. J. Holiman, and M. Blaese. 1976. Monocyte-mediated antibody dependent cellular cytotoxicity: a clinical test of monocyte function. Blood. 48: 809-816.

21. Abramson, N., W. E. Gelfand, J. H. Jandl, and F. S. Rosen. 1970. The interaction between human monocytes and red cells - specificity for IgG subclasses and IgG fragments.J. Exp. Med. 132: 1207-1215.

22. Victoria, E. J., E. A. Muchmore, E. J. Sudora, and S. P. Masouredis. 1975. The role of antigen mobility in anti$\mathrm{Rh}_{\mathrm{o}}$ (D)-induced agglutination. J. Clin. Invest. 56: 292301 .

23. Huber, J., S. D. Douglas, and H. H. Fudenberg. 1969. The IgG receptor: an immunologic marker for the characterization of mononuclear cells. Immunology. 17: 7-21.

24. Ross, G. D., and M. J. Polley. 1975. Specificity of human lymphocyte complement receptors. J. Exp. Med. 141: 1163-1180.

25. Rosse, W. F. 1971. Quantitative immunology of immune hemolytic anemia. II. The relationship of cell-bound antibody to hemolysis and the effect of treatment. J. Clin. Invest. 50: $734-743$.

26. Gilliland, B. C. 1976. Coombs' negative immune hemolytic anemia. Semin. Hematol. 13: 267-275.

27. Logue, G. L., and W. F. Rosse. 1976. Immunologic mechanisms in autoimmune hemolytic disease. Semin. Hematol. 13: 277-289.

28. Scornik, J. C. 1976. Complement-dependent immunoglobulin G receptor function in lymphoid cells. Science (Wash. D. C.). 192: 563-565. 